\title{
THE EMERGENCE OF AN “INTERSECTING CIRCLE" IN KACHRU'S Three Concentric Circles of World Englishes: A CASE OF EthNo-Linguistic NeUtrality in Central Nigeria
}

\author{
Peter Ochefu Okpeh, James Iorliam Udaa \\ Department of English and Literary Studies, Federal University Lokoja \\ peter.okpeh@fulokoja.edu.ng, jimudaah@yahoo.com
}

\begin{abstract}
There is evidence that contemporary Nigeria is drifting towards a society of monolingual English users, a component of which could be defined as lacking in ethno-linguistic identity. This trend is found among a generation of young Nigerian urban dwellers (between the age bracket of (12 and 25) who can neither communicate in their parents' native language(s) nor in any other Nigerian indigenous language; their only medium of communication is English. Although based on their childhood exposure to the English language and their relative competence in it, English can be described as their " "mother tongue" but the fact that they are not native speakers given the socio-geographical circumstances of their birth excludes them from Kachru's (1988) Inner Circle classification of native speakers. Consequently, these Nigerians are left without a clearly defined ethno-linguistic affiliation. This paper interrogates this emerging sociolinguistic phenomenon in especially Central Nigeria, with the aim of stimulating scholarly consciousness on the ethno-linguistic identity of this category of Nigerians, and its implications for English usage among them. The submission of the paper is that another circle, "the intersecting circle", be created for them since they bestride both the inner circle in having English as their "mother tongue" and yet they are not native speakers of the language.
\end{abstract}

Keywords: Mother Tongue, Ethno-linguistics, Ethno-linguistic Identity, Nigerian English

\section{INTRODUCTION}

The connection between language, culture, and identity is a widely researched theme in sociolinguistic scholarship (John, 1956; Trudgil, 1971; Kramsc, 1993; Uderhill, 2015). Most of the scholarly postulations on these variables situate language in between the two, and consider it as only the verbal expression of culture, but also a vital component of it as well as an index of identification among ethno-linguistic groups. Adegbite and Akindele (1999) explain this connection in three ways: first, language, according to them is an aspect of culture, one of its very many objects and institutions. Second, language is an instrument of thought, helping to concretise thought and to explore and record the experiences of culture. Finally, language expresses culture, and serves as the only means by which the social experiences and values of a group of people are perceived and understood.

The significance of language to its owners is further underscored by the Sapir-Whorfian hypothesis of linguistic relativity which describes the connection between the structure of a language and a people's worldview. A people's language, according to the hypothesis, conditions their conceptualisation of the world and influences their cognitive processes and behaviour. Language in this connection is critical to both how the individual members of an ethnic group define their identity vis- a vis their role within the group, and how the group in turn is able to project their cultural worldview and heritage among other ethnic groups and on the global stage. It is in the light of such a pivotal role of language to the ethno-linguistic uniqueness of the people that, in spite of the increasing linkages among the nations of the world being facilitated by globalisation, a cross section of sociolinguists has continued to advocate the need for linguists and governments of nations to do something drastic in order to reverse the threat of endangerment and death faced by most languages in Africa (Mufwene, 1995; Kraus, 1992, Stiglitz, 2002). The general thinking among such linguists is that whenever a language goes extinct an entire way of thinking is lost.

The current enquiry springs from the above orientation and is rooted in the hypothesis that a generation of Nigerians is currently emerging whose language behaviour makes it difficult for them to be classified under any existing ethno-linguistic group in Nigeria. This category of Nigerians whose existence in Central Nigeria also suggests the possibility of their existence in other parts of the country is within the age bracket of 12 and 25 years. Apart from their inability to speak their mother tongue, the only language they speak is English. However, the fact that they are not native speakers of English, based on Kachru's concentric circle theory of world Englishes, coupled with the Nigerian content of the variety of English they speak makes it difficult to consider English as their mother tongue, even though 
English is their first language. The complexity of their ethno-linguistic identity is further deepened by their inability to speak any other indigenous Nigerian language. The goal of this study is to interrogate this emerging linguistic phenomenon by stimulating scholarly conversations on the ethno-linguistic identity of the category of Nigerians that manifests this language behaviour, and its implications for English language usage among them, the Nigerian society and the global community of English language users.

\section{MATERIALS AND METHODS}

\section{I.1 Review of Related Concepts}

One of such concepts is ethno-linguistics which is the scientific study of the relationship between language and culture. Uderhill (2015) describes it as cultural linguistics, a subfield of linguistics that studies the way perception and conceptualisation of people influences their language. Uderhill (2015) further considers it to be how language relates to culture especially in relation to how meaning is politically and culturally influenced; how language shapes the thoughts of ethnic groups and how their thoughts in turn shape their language. In ethno-linguistics, language is considered as an integral part of culture. In relation to identity, Gile et al. (1977) define ethno-linguistic identity as what makes an ethnic group "likely to behave as a distinctive and active collective entity in intergroup situations. It is a sociolinguistic necessity borne out of ethno-linguistic diversity. This perhaps is why Tafel (1978) views it as an aspect of social identity which informs an individual's self concept and is derived from his knowledge of his membership of an ethnic group. The three aspects of social identity- cognitive, evaluative and emotional- outlined in Ellermers (1999) are, according to Ehala (2009) significant components of ethno-linguistic identity in that they enable the members of an ethnic group to act collectively as one. The pervasive impact of globalisation on the world's languages which manifests as "cultural imperialism" makes the question of ethno-linguistic identity not only a necessary way of ensuring the survival and perpetration of the diverse but rich cultural heritage contained in the over 7000 languages of the world, but also significant for individual ethno-linguistic groups as a means of defining and projecting their distinctiveness amidst other language groups.

Another of such concepts is mother tongue/ first language. The terms mother tongue (MT) and first language (L1) are often used interchangeably. Akindele and Adegbite (1999) support such usage and consider the two terms not just to have the same? meaning technically, but to also both have shades of other meanings and applications. First, the two terms according to Akindele and Adegbite (1999) refer to the only language of a monolingual person which is acquired naturally in his native environment, and is able to meet all his linguistic needs. Hebrew Language to a child born and bred in Israel will be the child's mother tongue/ first language because that is the only language he has in his speech repertoire and the only means of communication available to him. Akindele and Adegbite (1999) also consider a mother tongue/ first language to be the sequentially first language of a bi/multilingual person. Such a language usually fully identifies with the personal or native culture of such a person. A Nigerian, for instance, who is competent in Idoma, Hausa and English will be said to have Idoma as his mother tongue/L1 if Idoma is the language he acquires first among the three. Finally, Akindele and Adegbite (1999) consider a mother tongue/ first language to be the language in which a bi/multilingual conducts his everyday activity and which he has the greatest facility or intuitive knowledge. He uses such a language at both formal and informal settings and does not have to resort to texts in order to understand the phonology or syntax of the language. This is certainly what the English language is to an educated English man.

Language Acquisition is an unconscious process, very much a part of the entire developmental process of humans, by which a child internalises the linguistic behaviour of his environment (Chomsky, 1965; Shatz, 2007). Through language acquisition the young human acquires the capacity to perceive and comprehend language, as well produce and use words and sentences to communicate. Unlike language learning, language acquisition is usually informal and a product of social interaction in the linguistic environment of the child. Chomsky's Acquisition Theory explains how infants are born with a language acquisition device (LAD), an area in their brain which makes language acquisition a natural event. Based on the theory, a normal child naturally acquires the language of his environment by the time he is six. Language learning on the other hand is a conscious exposure of humans (who have assumedly acquired a first language) to the rules of a language. Unlike language acquisition which is motivated by the need to communicate and which occurs informally, language learning is borne out of official necessity and usually occurs within a formal institution such as a school where the learner is 
instructed on the rules of correct usage in the target language, which is usually a second language to the learner.

Another related concept is Nigerian English, which Jowitt (1991: x) metaphorically describes as "an English that has England as its first mother and Nigeria as its second, and has defied nature by undergoing a gynaecological reprocessing". Adeniyi (2006: 25) considers it to be the variety of English spoken and used by Nigerians. Jowitt (1991) considers it as being different from Nigerian Pidgin on the one hand and Standard British English on the other. One of the earliest postulations in favour of the existence of a variety of English known as Nigerian English is captured by Walsh (1967, p. 88) "the varieties of English spoken by educated Nigerians, no matter what their first language, have enough features in common to mark off a general TYPE, which may be called Nigerian English"'. Because of the varying sociolinguistic and educational backgrounds of Nigerian users of English, scholars on the subject have devised a couple of descriptive terms to qualify it. Banjo (1981) proposes "Standard Nigerian Spoken English", Bamgbose (1982) speaks of "Educated Nigerian English" and Jowitt (1991) contains these descriptive terms, and also has another descriptive label, "Popular Nigerian English". The foregoing are efforts by scholars interested in the phenomenon to conceptualise a "prestigious" variety of Nigerian English that will serve as its Standard form, and whose canonical parameters in the areas of syntax, phonology, semantics and lexis will form the basis for determining the non-Standard form of Nigerian English. Although the above does not seem to exist in a formal/ official sense, evidences of its consciousness abound in practice, in that the variety of English spoken by children of educated Nigerians is likely to be more "prestigious" (tending more towards Standard British English) than the variety spoken by their counterparts from illiterate backgrounds.

\section{I.2 Kachru's Concentric Circles of World Englishes}

Kachru's (1988) Concentric Circles of World Englishes proposed one of the most significant frameworks for classifying the varieties of English in the world. In the framework, Kachru conceptualised the spread of English in terms of three concentric circles, which are representative of "the type of spread, pattern of acquisition and the functional domains in which English is used across cultures and languages" (p. 12). The Inner Circle, according to the model, represents the traditional roots of English occupied by mother tongue varieties, where English has the status of a first language. Members of the Inner Circle are the UK, the USA, Canada, Australia, New Zealand. The varieties used among the members of this Circle are said to be the "norm- producing" varieties. The Outer Circle, according to Kachru, comprises earlier phases of the spread of English in non-native settings where the language has become part of the country's chief institutions, and plays an important second language role in a multilingual setting. Most of the members of the Outer Circle are former colonies of the USA and the UK, and include Malaysia, India, Singapore, Ghana, Kenya, and Nigeria. The varieties of English used by the members of this Circle, according to the theory, are "norm- developing". In the Expanding Circle are found countries where English occupied the status of a foreign language in terms of teaching and learning. They have no history of colonisation by members of the Inner Circle. Members of this Circle include China, Japan, Greece, Poland, among others. The varieties of English they speak are "norm-dependent". These three circles are represented in the figure below: 


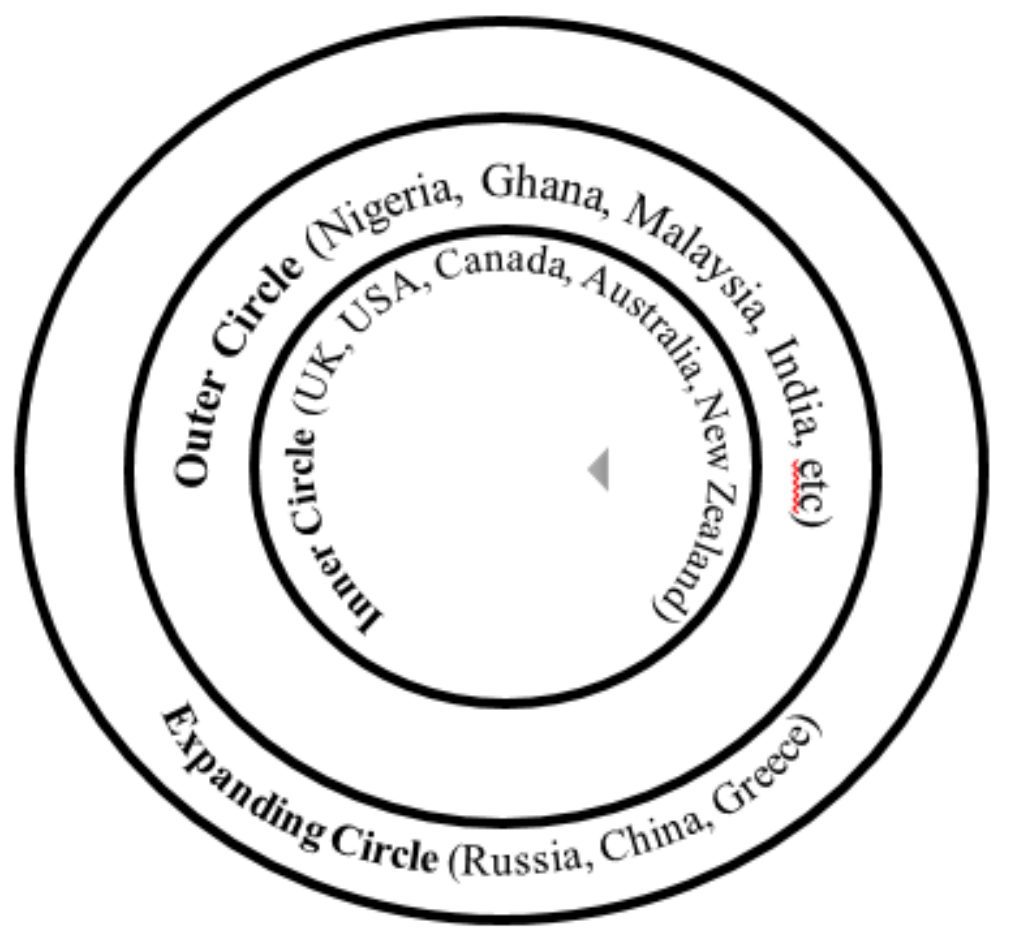

Fig. 1: Kachru's Concentric Circles of World Englishes

\section{I.3 Methodology of the Study}

This study is a pilot study and so the methodology adopted for it is a tentative reflection of the bigger study which is still ongoing. Although the target area for the bigger study is Central Nigeria, comprising Kogi, Kwara, Niger, Nasarawa, Plateau, and Benue, attention is currently being focused only on Kogi and Benue States. Kogi is chosen because of not only its strategic placement in the country's geo-sociopolitical history, but also because the researchers currently reside and work in Lokoja, the state capital. Benue's selection is informed by the fact of being the researchers' state of origin where they have had considerable contact with members of the target group in question. A total of 150 people between the age bracket of 12 and 25 years old from these states are being engaged with regards to their spoken English. The mother tongues of the parents/ guardians of these people are Igala, Ebira, Okun, Idoma and Tiv. The instruments of data collection are observation, informal interaction in the form of participant observation where the subjects are unaware of the purpose of the interaction. The interactions bothered essentially on some of the social and political issues that were prevalent in Nigeria at the time of the research. The purpose of such informal interactions was to elicit a plethora of linguistic forms from the subjects which provided a sociolinguistic framework to classify them. The semi-structured interviews were administered to both the subjects and their parents/guardians. The interviews were designed to obtained information on their biodata and sociological / sociolinguistic issues bothering on the language of their highest proficiency, the mother tongues of their parents (if parents are from different ethnic groups), etc. From the outcome of these dimensions of engagement with the subjects, they can be tentatively classified into three sociolinguistic groups.

GROUP A: Those whose parents/guardians are from the same ethnic group, yet their indigenous languages are hardly ever used in communication between the parents, nor by such parents to their children. Consequently, English is the only medium of communication in such homes.

GROUP B: Those whose parents /guardians are from the same ethnic group (like in Group A above) and use their indigenous language to communicate between each other and to their visiting relatives, but resort to English when they want to interact or communicate with their children/wards. The children in turn use English in communicating with their parents and interact with their siblings.

GROUP C: Those whose parents /guardians are offspring of mixed marriages (e.g. one of the partners is from Kogi State and the other, the indigene of another state). This group, like the first two, is hardly ever communicated to in either of their parents' languages; thus they are left with only English as the medium of communication especially as the parents themselves necessarily have to rely on English for interpersonal communication between each other. 
For a better understanding of the above classification, none of the youths in the three groups above, during the period the researchers interacted with them and based on the authority of their parents' statements, produced code switching or code mixing during their conversations in English.

\section{I.4 Theoretical Orientation}

The theoretical framework underpinning this study is the Languages in Contact Theory which provides a basis for a comprehensive investigation of the changes experienced by languages when they interact in multilingual contexts. According to Moumine (2020), there has been an unprecedented growth in the study of languages in contact. Thus, given the influence of multilingualism as a result of globalisation, Clyne (2003 as cited in Moumine, 2020, p.1) LIC is "a multidimensional multidisciplinary field in which interrelationships hold the key to the understanding of how and why people use language(s) the way they do. This includes interrelations between the structural linguistic, sociolinguistic and psycholinguistic; between typology and language use; between macro- and micro dimensions; between variation and change; ... between the linguistic, sociological, demographic and political". Clyne posits further that a direct consequence of LIC is bi/multilingualism in which the implication of any analysis of contact situations may stand in support of the sociolinguists' assumption which argues for the existence of a patterned interaction between language and its users. Consequently, the study of LIC has become a fresh frontier for research where the synchronic and diachronic analyses of languages converge and offer further evidence for the dynamic nature of language (Martinet, 1955; cf. Thomason, 2001; Winford, 2003, as cited in Moumine, 2020). This theory is therefore suitable in undertaking this study because of the new insight being investigated by the phenomenon of non-native mother-tongue English monolingual speakers in Central Nigeria.

\section{RESULTS AND DISCUSSION}

\section{II.1 Indicators of Subjects' Ethno- linguistic Neutrality}

The first and most prominent indicator of the neutrality of the ethno -linguistic identity of these Nigerians is their inability to communicate neither in their parents' indigenous languages nor in any other Nigerian indigenous language. Ethno-linguistic identity is a consciousness rooted in ethnolinguistic group membership, and since a cardinal feature of this membership is the ability to communicate in the language of the group, subjects in this category are without a clearly defined ethnolinguistic membership, as they are unable to lay claim to any Nigerian language as their mother tongue. The potentiality of language as the vehicle of culture and marker of identity gives these Nigerians out as being short of the Nigerian culture sociolinguistically. Consequently, although their parents may be affiliated to certain Nigerian ethno-linguistic groups, they themselves cannot be said to share their parents' linguistic identity, especially as language is not genetically transmitted.

Another indicator of the ethno-linguistic neutrality of the subjects in all three groups is the circumstance of their nationality and their consequent placement within the framework of Kachru's three concentric circles. Granted that English is their first language, and could in a technical sense be regarded as their "mother tongue" especially as it was, like every other mother tongue, naturally "acquired" by them, the fact that they are nationals of Nigeria excludes them from the Inner Circle of native speakers where nationals of countries such as the USA, the UK, Canada, Australia, and New Zealand belong. Consequently, they cannot be given the Inner Circle status (because they are not native speakers), neither can they be accurately described as belonging to the Outer Circle (because they "acquired" and did not learn' 'the English language).

The ethno-linguistic neutrality of the subjects in Groups A, B and C, is further revealed by the variety of English they speak. The varying nature of their sociolinguistic and educational background when situated against the efforts of some Nigerian linguists to conceptualise a "standard" or "educated" or "popular" variety of Nigerian English further deepens the difficulty of associating them as a group with one singular variety of Nigerian English. There are varying degrees of perfection/ imperfection in their spoken English which can only be reflective of their sociolinguistic and educational backgrounds. Thus, their variety of English has a "fluid"' and an emerging nomenclature, neither clearly collectively defined as "Standard Nigerian English", nor anything close to the variety spoken by Kachru's Inner Circle members. Recorded samples of their oral communication, for example, reflect phonological patterns of the language of the dominant ethnic group in the area where they are domiciled as well as syntactic and lexico-semantic manifestations. 
From the methodology adopted for the study, it was observed that at the phonological level, the subjects display some mastery and a degree of proficiency beyond the various ethnic Englishes across Nigeria such as Hausa English, Yoruba English, Igbo English, Ebira English, Igala English, Idoma English, Tiv English, and so on. Their accent is relatively unmarked at both segmental and suprasegmental levels, cutting across a large spectrum of the Nigeria speech community. It is quite difficult from their articulation to pin them to a particular ethnic identity. The general features at segmental level manifest in vowel reduction where tense (long) vowels are made lax (shortened), systematic substitution of certain consonants, reduction of consonant clusters while at the suprasegmental level observable patterns include bisyllabification of monosyllabic words, a tendency to overgeneralise the rules of stress patterns, and general realisation of only the falling and rising tone in intonation pattern. Features predominant at the syntactic level include noun subject copy, pluralisation of non-count nouns, omission of obligatory articles, morphological processes such as reduplicatives, etc. Lexico-semantic features of English include their use neologisms, semantic extension, semantic restriction, etc.

\section{II.2 The "Intersecting Circle" as the Fourth Circle in Kachru's Three Centric Circle: A Proposed Modification}

The analysis made so far already demonstrates the complexity of the ethno-linguistic identity of the category of Nigerians in question and the difficulty to situate them in any of Kachru's three concentric circles of World Englishes. Clearly, the foregoing hinges on the dynamic interplay between language contact and language change. And so nearly three decades now after Kachru propounded his three concentric circles of classifying World Englishes, the English Language has interfaced with more climes across the world and undergone radical transformations as a result of these contacts, such that new varieties are constantly emerging, some with ethno-linguistic roots which Kachru did not envisage when he conceived his model. In what follows we attempted a modification of Kachru's three concentric circles in order to create a space for the group we have described in this study as being ethnolinguistically neutral. In our proposed framework, there is a fourth circle which bestrides both the Inner Circle and the Outer Circle. We name this new circle "the Intersecting Circle". It is "intersecting" because it overlaps and bestrides both the "Inner and Outer circles", and by so doing it appropriately captures and accommodates the multiple ethno linguistic- characteristics of its members such as:

\footnotetext{
i English is their "mother tongue" (a characteristic of Inner Circle members), yet they are not native speakers of the language.

ii. They (as Nigerians) are nationals of a former colony of Britain (a requirement for belonging in the Outer Circle), yet English is their first language.
}

Against the backdrop of their sociolinguistic characteristics above, a way to define the paradox of their ethno-linguistic identity and characterise their placement in Kachru's three Concentric Circles framework will be to conceptualise an overlapping space for them among the first two circles of world Englishes, which is what has been proposed in this paper. This is diagrammatically represented below: 




Outer Circle

(Nigeria, Ghana, Malaysia,

India, etc)

Inner Circle

(UK, USA, Canada, Australia, New Zealand)

\section{Intersecting Circle}

(Nigeria, $\mathrm{X}$ )

Expanding Circle

(Russia, China, Greece)

Fig. 2: A Modified Version of Kachru's Concentric Circles of World Englishes

( $\mathrm{X}$ in the Intersecting Circle represents other countries in West Africa and elsewhere, which might be experiencing similar sociolinguistic developments)

\section{CONCLUSION}

Language and language contact is critical to ethno-linguistic identity and also constitutes the lens by which ethno-linguistic groups conceptualise the world. The study examined emerging indices of ethno-linguistic neutrality among a group of English users in Central Nigeria, with Kogi and Benue State as pilot study which constitutes a microcosm of the wider group of similar Nigerian English users across other parts of the country. Findings revealed the complexity of their ethno-linguistic identity and the difficulty of locating them in Kachru's (1988) concentric framework of World Englishes. Consequently, the study proposed a modification of Kachru's framework to include a fourth circle which bestrides the first two circles in the original framework, and consequently defines a space for this group of Nigerians in the global community of English users.

\section{REFERENCES}

Akindele, F. and Adegbite, W. (1999). The Sociology and Politics of English. Ile-Ife: Obafemi Owolowo University Press.

Banjo, A. (1981). "Towards a Definition of Standard Nigerian Spoken English" in Actes du Congres de Societe Linguitique. Abijan: University De Abijan

Bamgbose, A. (1982). Standard Nigerian English: Issues of Identification. In B. B. Kachru (Ed.), The Other Tongue: English across Cultures (pp. 95-111). Illinois: University of Illinois Press.

Chomsky, N. (1965). Aspects of the Theory of Syntax. MIT Press.

John, B. (1956). Language, Thought and Reality: Selected Writings of Benjamin Lee Whorf. New York: Technology Press of MIT.

Jowitt, D. (1991). Nigerian English Usage: An Introduction. Lagos: Longman.

Kramsc, C. (1993). Context and Culture in Language Teaching. Oxford: Oxford University Press.

Kraus, M. (1992). The World's Languages in Crises. Languages.

Kachru, B. (1988). "Standard, Codification and Sociolinguistic Realism: The Language in the Outer Circle. In R. Quirk \& H. Widdowson (eds.) English in the World. Cambridge: Cambridge University Press.

Mufwene, S. (1995). "Language Shift \& Language Death: Perspectives from new Worlds". A Paper Presented at the Language South of Rio Bravo. Conference: 9-10 January, 1995

Moumine, M.E.A.(2020). “ The Theoretical Approaches to the Study of Language in Contact" In Basa Mat.(P.1-28) 
Shatz, M. (2007). On the Development of the Field of Language Development. In Holf and Shatz (Eds.). Blackwell Handbook of Language Development. Wiley. pp. 1 - 15.

Stiglitz, J. (2012). Globalization and Its Discontents. New York: Norton.

Tajfel, H. (1978). "'Social Categorizations, Social Identity and Social Comparison" In Tajfel (ed) Differentiation Between Social Groups: Studies in the Social Psychology of inter group relations. London: Academic Press.

Trudgil, P. (1971) Sociolinguistics. Hamondsworth: Penguin.

Uderhill, J. (2015). Ethno-linguistics and Cultural Concepts. Cambridge: Cambridge University Press. 
